DOI: https://doi.org/10.47405/mjssh.v6i8.931

\begin{tabular}{|c|c|}
\hline 4 & Malaysian Journal of Social Sciences and Humanities (MJSSH) \\
\hline $\begin{array}{l}\text { Malaysian Juoural of } \\
\text { Social ccciecces and }\end{array}$ & Volume 6, Issue 8, August 2021 \\
\hline (MJ-sSH) & e-ISSN : 2504-8562 \\
\hline & $\begin{array}{l}\text { Journal home page: } \\
\text { www.msocialsciences.com }\end{array}$ \\
\hline
\end{tabular}

\title{
Feminism and a View of Conservative Gender Roles among Young Working Women in Malaysia
}

\author{
Goh Ian Shen'1, Janak Ashok Teckwani' ${ }^{1}$, Nicole Lee Yuk Cheng1, Ku Ze Ren¹, Kezia George1, \\ Pang Chia Yee ${ }^{1}$ \\ ${ }^{1}$ Faculty of Social Sciences and Leisure Management, Taylor's University Lakeside Campus, Malaysia
}

Correspondence: Pang Chia Yee (ChiaYee.Pang@taylors.edu.my)

\begin{abstract}
People are often influenced by norms and ideologies, including the concepts of feminism and conservative gender roles. With perceptions evolving constantly, we intend to investigate the subject of feminism and the view of young working women in Malaysia with regards to conservative gender roles. Studies on the subject have been scarce or minimal so far, hence understanding the general population's perception will allow us to better measure public awareness on the topic of our research. The demographic of participants in this study specifically encompasses working women, between the ages of eighteen and forty years old. The participants were recruited through virtual mediums, namely WhatsApp, Facebook and Instagram. They were then asked to participate in a semi-structured interview to aid in the collection of detailed data which was then analysed through the process of transcription and coding for recurring themes. The study suggests that young working women in Malaysia are more in tune with feminism than originally anticipated due to digital platforms. Among the inequalities faced in the workforce, the most cited are equal and fair pay. Family upbringing, tradition and culture were often cited as shaping the general evolution of gender roles. Research can be done on feminism, gender roles and their implications on the LGBT community as a whole.
\end{abstract}

Keywords: feminism, gender roles, working women, Malaysia, conservational

\section{Introduction}

Feminism is a widely debated topic around the world, as the movement grow stronger in countries like the United States. Defined as the advocacy of women's rights on the equality of the sexes (Feminism, 2019), it is also known as a common term for intellectual traditions, ethics, ideologies and social and political movements that focus on equality, fairness and freedom for each (Beasley, 1999). Despite the advancement of the movement in other countries, Malaysia struggles to catch up with the changing times. The nature of women in the workforce has been widely contested in Malaysia due to conservative views within the country. In the Global Gender Gap Report 2020, Malaysia is listed as country 104 out of 153 in its Gender Gap Index ranking, making it the third lowest country in ASEAN on the scale. Moreover, the Doraemon issue thrust Malaysia into the spotlight when a local ministry began issuing tips for Malaysian women to 'talk like Doraemon' to appease their husbands during the COVID-19 movement control order. This piqued our interest as researchers to investigate the views of young working women with regards to conservative gender roles, and how they correlate to feminism. 


\section{Literature Review}

Feminist theory deals with the extension of feminism into multiple discourses, namely philosophical, theoretical and lastly, fictional. (Yick, 2001). The variations of feminism through the times are as follows:

Liberal feminism is first established in the 18th century, and it was through this Enlightenment that the associated ideals and thoughts of equal rights and liberty arose (Mann \& Patterson, 2016). At this period, the definition of equality between genders is challenged, as well as society's patriarchal structure that had been imposed onto many aspects. Next is radical feminism, which challenges the centrality of men and oppression of women, and demands the dramatic transformation of men and masculinity. Psychoanalytic feminism explains that ending women's oppression cannot depend on sociological aspects alone (Mitchell, 1974), but also understanding the unconscious, internalised ideologies within women. In short, it is about understanding the roots of the problem-, and then solving it. Multidimensional feminism acknowledges a variation of masculinities where different masculinities go hand in hand (Ramazonoglu, 1992). Lastly, postmodern and poststructuralist feminism, emerging in the 1980s to the 1990s, offers new methods of analysing and conceptualising gender, and works towards identifying neglected, silenced, or taken for granted thoughts about genders (Brown, 2019).

One of the newest progresses of feminism is digital feminism, which tackles online misogyny. The fourth way of feminism has very much moved into a digital battlefield, namely the Internet, but just as many problems arise with this wave, including inconsistent regulation, and online and offline abuse (Jurasz, 2019). Feminism has also found its roots into many aspects, such as its correlation with criminology and even dynamic differences in translations of texts by males and females (Qiu, 2019).

Despite the core of feminism being a straightforward concept, its various waves have led to varying definitions, or more instances of misinterpretation or abuse through social media. An abundance of concepts and definitions flourished, and many feminists apply their variation of feminism as a cause to their actions and movements, creating numerous contradictions amongst themselves especially on online platforms, and confusing others who try to wrap their heads around this concept.

This has caused many to attribute stereotypes to feminists. Non-feminist men were typically seen as less feminine than feminist men were. Feminist men were often perceived as lacking in masculinity. Female feminists, on the other hand are deemed more masculine than their non-feminist counterparts, which are being agreed across men, women, and people possessing hostile sexism (Gundersen, 2018).

In the context of education, which has been a resourceful avenue for the work of feminists for an extended period of time, both elements of education and feminism have recently taken up practices and methods such as poststructuralism, post-colonialism, post-emancipatory, post-foundational, postmodernism, and post-revolutionary (Pierre, 2000).

From a worldwide and multicultural perspective, feminism progresses differently everywhere, with some boldly fighting for it in the political fields, to some still battling domestic violence and patriarchal oppression, and some not even to beginning to have any awareness at all. A contrasting example to such modern forms of feminism would be Iran's fight against religion's grasp over women, and men superiority (Ali, 2019). In the Asian context, situations prove to be very different, as feminism and traditional cultures have a close-knit relationship. Cultural studies are almost always taken into consideration, or generally linked with the study of feminism in Asian countries, as the diversity of it contributes a great deal towards the formation and progression of feminism in Asia (Niranjana, 2007).

As Malaysia is a postcolonial country, both genders were granted the right to vote during the country's political independence (Ariffin, R., 1999). Initially, the first documented use of women's liberation or more accurately, women's emancipation were by Muslim male reformers who advocated education for both women and girls (Izharuddin, A., 2013). Similarly, post-war circa 1946 to 1948, women from different ethical backgrounds mobilised together in an effort to confront anti-colonialism and issues related to women's inferior status in early Malaya. Recently, sexual abuse and domestic violence 
against women as well as child brides, marriages and forced marriages remain current heated topics in modern Malaysia. Conversely, in 2007, AWAS (All Women's Action Society) was founded as a shelter for Malaysian women who needed legal consultation and protection. This, in turn, generated very few official Malaysian studies on feminism, with more significant ones revolving only around feminism's definition, history, waves, and current progresses.

Another field worth mentioning would be female's everyday issues with socially assigned gender roles, gender traits, and stereotyping. Gender roles would be defined as the role or behaviour that a person learns which can be seen as appropriate to their gender, due to prevailing cultural norms whereas stereotypes is explained as popular but fixed and oversimplified ideas of a specific type of thing or person (Oxford, 2019). These mindsets contribute to the appearance of glass cliffs and glass ceilings in the workplace, which is one of the key points in this research: gender equality in the working environment especially in terms of pay gap and abilities. Empirical research has proven that managerial jobs or executive oriented jobs are always considered male jobs, in which this form of stereotype makes it even harder for females to climb up the organisational hierarchy. There is fluctuation in the extent to which a particular occupation is characterised as dominantly masculine, based on aspects such as work product, specific functional area of management, or work sector or domain (Heilman, 2001).

Stereotypes regarding women in leadership positions are even more common, and receive more publicity through different forms of media such as newspapers. The 'iron maiden', or the 'battle axe', as according to Kanter's four stereotypes, are commonly attributed to feminists, or women in leadership positions. Comments for 'iron maidens' by their colleagues are routinely represented as 'scary', 'tough', 'bully', 'mean', 'calculating', 'hard to deal with', and even to the extent of 'bitchy' (Baxter, 2010).

In a family setting, especially in Malaysia, the patriarchal oppression is much stronger, and is furthermore endorsed by many parties. One of them being the Ministry of Women, Family, and Community Development, which published on social media a set of guidelines for females on 30th March 2020 during the movement control order period amidst the COVID-19 outbreak in Malaysia. The guidelines were issued on both Facebook and Instagram, meant for wives as recommendations to manage their households, and prevent arguments with their husbands. According to the Malaysian newspaper, The Star, the tips are as followed: Wives should not make sarcastic comments if their husbands are not helping with the housework, and instead should inform them in a humorous manner, and speak in a pleasing, Doraemon-like tone. Should arguments arise between wife and husband, the wife should count from one to twenty before giving a response, to give the brain time to become more rational and calmer in decision making. Wives should also avoid wearing home clothes, and dress formally, as well as put on make-up, to give a better visual representation towards their husbands. Working mothers should keep the kitchen, living room, and dining room clean and neat to help maintain a tranquil state of mind while working from home. The Star has deemed these messages as 'chauvinistic' and 'sexist'.

The post received much backlash, and was removed the day after with a public apology. Many individuals and parties supporting equal rights also stood up to voice out, or propose a more suitable set of guidelines for families. The majority of Malaysians were unable to comprehend the reference to Doraemon. Moreover, many were outraged by the ministry trivialising the issue of gender equality and domestic violence especially during the MCO in which victims of domestic violence are extremely vulnerable. For a ministry dedicated to protecting women, families, and community development to release such statements indicates a mindset of unawareness of feminism, and compliance to traditional and conservative gender roles.

\section{Methodology}

\section{Participants}


The researchers ensured that the participants fit the required demographics which comprised Malaysian women between the ages of eighteen to forty, preferably working and earning an income or have had working experience in any field of a specific company. Concomitantly, it was also decided that participants who have or have had male colleagues in their working environments should be scrutinized, as the questions of the interview insinuated a comparison between male and female colleagues in their salary or income. Should the individuals express disinterest or uneasiness when approached about participation, the researchers understood their circumstances and moved on to other potential participants as feminism and gender roles, as a whole, can come off as a taboo subject, which make it a topic that is sensitive to discuss (Zucker \& Bay-Cheng, 2010). Participants were recruited through a variety of social media platforms, namely Facebook, Instagram and WhatsApp.

\section{Method}

Considering that the topic has a very subjective take to it, it was decided that a semi-structured interview would be designed to encompass an equal ratio of questions on topics surrounding feminism and conservative gender roles respectively. Prior to the development of the interview questions, the authors extensively researched existing materials based on the topic of this study. There were limitations in resources as it was realised that there were only a few journals on feminism and gender roles in the country. Hence, the researchers were obligated to compile journals from a multitude of different countries to aid in referencing. From the list, the focus of the articles was segregated into their specific themes and study analyses; it became less intricate to scrutinise the details. While brainstorming during the process, both knowledge and open-ended questions were developed. This was done with the idea that if any of the researchers needed to understand more of the participant's perspective in detail, they had the ability to ask probing questions. Some of these probing questions involved examples and further explanations for more elaborate detail on the participant's answer. The idea was to tackle initial perceptions, thus straightforward questions were asked about the participants' thoughts on feminism and conservative gender roles in the country and how it affected them, directly or indirectly. Participants were also probed by the researcher for real-life examples to understand more on their views, knowing that different individuals have different experiences. The questions were also constructed to be as clear and concise as possible for the participants to understand. A copy of the developed question sheet is attached in the appendix of the report for reference (Appendix A).

\section{Procedure}

Participants were provided with the options to be interviewed through a video or audio meeting using online conference platform, Zoom. The interviews were held privately and confidentially, lasting for an approximate time frame of fifty minutes, including breaks in between due to technical issues such as network connectivity during the session. All interviews were recorded and transcribed verbatim. While analysing the data within the transcripts, the authors abstained from paraphrasing the quotes of participants to preserve authenticity. Before commencement of the interview, participants received a digital copy of an informed consent form containing details of the interview, such as the purpose, recording process, and an estimated time frame. The participants were assured of confidentiality, anonymity as well as having the right to withdraw from the research at any point in time if they were to feel uncomfortable during or after the interview. They were also assured that they were entitled to refuse being video recorded. Four participants refrained from being video recorded and their interviews were instead audio recorded. To preserve the anonymity of the participants, all sixteen participants were identified through pseudonyms. This study has received full approval from the Research Ethics Committee of Bachelor of Psychology (Hons), Taylor's University, Reference number: HEC 2020/045. A copy of the complete transcript is provided within the appendix attached to this report for reference (Appendix B). Moreover, a copy of the approval from the Research Ethics Committee of Bachelor of Psychology (Hons) is included for reference (Appendix H). Finally, the participants were presented with a Debriefing Script and Service Sheet after the interview was over which can be found in Appendix F and G. 


\section{Data Analysis}

The researchers conducted a thematic analysis to examine the data collected from the participants' answers as it was suitable to the research goals, and also functioned as a flexible research tool which might enable both social and psychological interpretation (Braun \& Clarke, 2006). An inductive approach to theme analysis was used to identify emerging themes that corresponded to the data of this research. This approach was used to make sure that the themes were based upon the participants' own narrative, and not impacted by the researchers' grounding in the feminist theory. The researchers went through the text and took notes on the participants' quotes to group the text together and produce preliminary codes. These codes were used to acquire a concise summary of common meanings and key points, as well as represent patterns that recur within the data which may reflect on the reasoning that the participants used to rationalise their views. This method of coding was comprehensive as the codes were used in reference to the quotes of the majority of participants. The researchers then organised the coded text into a spreadsheet and classified them into potential themes. To assist the researchers in organising the potential themes into sub-themes, a thematic table was developed, which can be found in Appendix I (Braun \& Clarke, 2006; Elder \& Miller, 1995).

\section{Results}

The themes identified in the analysis of the raw data obtained by interviewing and coding the 16 participants who partook in this study are Equality and Support of Women's Rights, Evolutionary Changes in Norms of Conservative Roles and Women in Positions of Power Disseminate Obsolete Information on Gender Roles. These themes are able to answer our research question as it discusses several aspects of Feminism and Gender Roles from multiple point of views. For example, personal background, culture, religion as well as power and authority. Moreover, within each superordinate theme, there are two to three more sub themes that help explain the theme in more detail. While there are similar responses from some participants that may be generalised into a majority, there are outliers that help answer unique perspectives on the issues at hand.

\section{Equality and Support of Women's Rights}

Women are faced with inequality on a daily basis within the family, work or society and aim for their rights to be heard and practiced. When asked "How would you describe feminism?", a majority of the participants define feminism in the most generic and straightforward manner where feminism means equal rights and opportunities and it was also expressed as a movement to rule out the systematic inequalities faced by women. It was also understood there seems to be a common misconception of what feminism truly means, as feminism is portrayed and misinterpreted on mass media as being matriarchal or oppressing males. "Ash", nineteen, felt that the word connoted a sense of superiority in females and stressed that it was a common misconception and that it should mean gender equality more than anything else:

“... It's actually just to bring females up to the equal point as males. Like some people think feminism is to make females as like the top of the hierarchy or something and then, like males who have stepped down or something."

\section{Gender equality and advocacy of women rights}

Most of the participants emphasised on how people they know and they themselves have had experiences of inequality at some point in their lives, because they are women, and wish to see a change in opportunities to do a variety of jobs or roles, or even in the responsibilities at home. Indeed, this is evident in the responses of our participants.

Every one of our participants spoke about how feminism means gender equality, but only two of our participants considered the LGBT community and shared their perspective on how their views are 
inclusive. The general perception of "Clarice", twenty-three, is that often, society and especially Malaysia, does not take into consideration the individuals who do not identify as either gender and so gender roles may not apply to them:

“...this becomes a problem because there are so many people nowadays that are gender neutral, what about the queer and the LGBT. You know, there are people that do not want to conform to a gender because they are gender fluid."

This brings up an interesting debate that is not covered in the scope of this research paper. Malaysia considers topics of the LGBT community as taboo or as a Western influence. However, it is interesting to see these two outlier participants who share very progressive views on the subject and even bring it up in the interview as a viable area of how conservative gender roles do not fit non-conservative individuals who do not adhere to said gender specific roles.

\section{Family background and upbringing}

Women expressed how their family upbringing helped pave their morals and values, but they also question them and evolve as they grow. A lot of stereotypical and traditional distribution of house chores were implied from childhood. Through discussion, the participants shared that this was due to how their mothers and families has been following these norms for generations and therefore continue to practice them. An interesting outlier was "Jo", twenty-seven, who shared how her parents were both educated and employed hence they were more open-minded. This is apparent that with education and awareness of globalisation, equality can be attained in all aspects. In her response, she was insistent on how it made not only herself but her brother respect gender as a whole and discount gender from societal importance,

“... she helped me and my brother see that, hey, you know what, no matter whether you're a male or female, you are equally important, and you can do whatever you want to do."

Furthermore, participants cited progressive parents and progressive education as widening their perceptions on acceptance. Indeed, another outlier, "Terri", twenty-one, stated that it was indeed her peers that influenced her previously shut off attitude to conservative gender roles and feminism when she was introduced to her friends who shared much different perceptions on said topics than her. She went on to argue the importance of exposing herself to different types of people and not staying in her comfort zone in order to achieve this realisation that she was living in a box of her own perceptions.

\section{Evolutionary Changes in Norms of Conservational Roles}

As times change, so does one evolve. Overall, participants shared how their views and stances on what feminism is and the conservative roles of males and females have evolved as they grew up. From facing their own difficulties and challenging social norms to getting educated and exposed to women who walk on different paths of life, these helped our participants to evolve from their traditionally taught and initial views on conservative roles. Our participants expressed how acquiring more education and knowledge about the topic and happenings around the world helped to expand their view, and they brought that back into their families, or wish to do so when they have children too. They believe that they can be the change-makers to break traditional roles and bring equality into their own circles. Participants also acknowledge the fact that the world is evolving so they need to act and behave accordingly in order to cope by doing more than that society asks for from women. In essence, this theme is mostly comprised of point-of-views of said women in their quest to change the norms of conservative roles that they may have themselves or that society has.

\section{Respect for equal treatment in relationships}

There was one participant who pointed out the fact that the question on how acceptable it would be in their household if the woman makes more for a living than the man shows how women are oppressed 
and not normally expected to make more than the men in their lives. Indeed, "Prash", twenty-seven felt that the need to consider the implications was more than enough to reflect the norms that provide obstacles to women and often impede on their success. It can be seen as unacceptable or odd for some families to the point that they are unwilling to be subjects in a topic such as this, which can sometimes be considered taboo. "Kamal", thirty-three, was most vocal about this:

“... I think this is more of an Asian uhh you know mindset, where you know, women have to earn much lesser and men have to earn more, and things like that. If suddenly they see the woman is earning more than they tend to compare, they tend to talk back you know"

The women that were interviewed believe that contributions to the family should not solely depend on the man, as at the end of the day, these contributions sustain the family, and both parties should be responsible for said sustaining. "Sha", twenty-seven, was quite vocal about this and did not entertain the idea of considering a partner as a future spouse unless he fit all these criteria, "... Yeah, and it was gonna be an issue to my future husband then he wouldn't even be my future husband".

\section{Fairness of salary based on education and expertise}

The participants shared they feel they get paid fairly in comparison to their male colleagues. However, these women shared how they knew of friends and other co-workers who face discrimination and have a huge pay gap between their friends or their male co-workers. Firstly, more companies and workplaces are acknowledging employees' educational backgrounds and as well as valuing talent or skills regardless of gender. Women also acknowledge the fact that they are paid according to what they can bring to the table. "Tina", thirty-two, went so far as to state that she had the power to determine how much she is paid due to her existing skills and expertise in the field of mental health as a profession.

"... I' $\mathrm{m}$ in the mental health profession. So in the mental health profession, you are... How we get our income is based on how much... What's the fees that we set for client. So we, we have a say in how much we want to get paid in some ways because of our skills and expertise."

Those getting a fair salary believe it is due to their experience, education and position in the company or firm. On the other hand, those who are not getting paid fairly expressed how they need to work harder and men are paid twice as much for the same position. This sentiment was shared in detail by "Sha", twenty-seven, who reiterated the effort needed to be put in by a female in order to compete with their male counterparts:

“...I feel like a woman, you need to do a lot more to prove what you're worth, and um, it's really a horrible feeling... They (men) don't need to prove themselves, so what they need to do is the bare minimum."

\section{Women in Positions of Power Disseminate Obsolete Information on Gender Roles}

Overall, participants shared quite disparate views on the statement made by the Women, Family and Community Development Ministry of Malaysia. Some were in support of the statement but were dissatisfied with the general execution of how the statement was made criticising one specific party in the relationship; the woman or wife. However, we see this contrasted with other participants who were outraged by the statement and called it bigoted or conservative mentality. This can be seen more clearly in the sub-themes analysed from this superordinate theme. There is one participant who strongly opposed at first and then realised that they agreed with it. They even rationalised the minister's statement and found that it was relevant in her household. However, she reiterated that the responsibility of avoiding conflict at home need not only be the burden of women but also of men. "Clarice", twenty-three, expressed that the statement being made by a woman in power demeaned efforts by feminists to push their agenda of equality as conservative gender roles can be used to 
oppress. "...believe that you are there in that position, you know, amongst how many men and the audacity for you to send out a statement like that just proves that feminism itself...gender roles, is flawed."

\section{Inappropriate Statements and Outdated Mentality}

The majority of the participants were upset and frustrated over the statement as they felt that the statement was not clever nor a joke, and even called it insensitive and a relic of an outdated mentality. A fair number felt it was degrading to women or falsely represented women and women in Malaysia as a whole. "Nic", twenty, felt that the conservative gender roles presented in the statement were demeaning and only pushed the narrative that women were to be objectified or considered as the weaker sex.

Another participant found it to be erroneous and likened the ministry telling women how to act to controlling their futures. Indeed, "Usha", thirty-one, felt that the ministry should have encouraged young women as well as those who are in a relationship to be independent. However, Usha found the statement made to be degrading and damaging to the mentality of women, conservative gender roles and the feminist movement. "...but to actually encourage everyone to do that its wrong, because that is not what we are meant to do, we are meant to also change the nation."

It was interesting to find that most, if not all, participants outright disagreed with the statement or at least expressed distaste at the execution of the message underlying the statement. In fact, two participants clearly remarked that they understood the message and felt it was exemplary that the ministry intended to encourage harmonious relations at home between spouses but the method of disseminating this information was erroneous. "Deidra", thirty-two, was vocal about the ministry having said message and could see the value in it:

“... I see where the Ministry of Women was coming from, in a sense that they wanted to- they wanted women to lay low and to not cause any fights by doing this, but it shouldn't just be the woman's responsibility!"

\section{Underlying Implications of Patriarchal System}

Many participants pointed out that the directive of the statement being angled at women in particular took the power away from them. They also agreed that the burden falling on the shoulders of women resulted in the opposite of the intended effect by the ministry and instead was detrimental to the overall safety and power struggle between the two genders in Malaysia as a whole. "Ash", nineteen, shared her view on the empowerment certain men may gain from such a statement. This could in turn lead to tumultuous household relations. This leads to the idea that they must be subservient to their husbands being ingrained and reaffirmed in their mind, and they now will not rebel against it as this must be considered the norm if the government of their country were the ones to release such a statement:

“...empowering men like those who actually already have a very traditional thinking that oh, we must, should do this and do that. So those men who read that will stand even more strongly on their own point of view, and then they would use that to oppress their own partners."

Throughout the discussion, participants were also more than willing to share their points of view on the power dynamics that would occur with a statement such as this. A prime example that came up was how the statement could easily be misconstrued to serve the biases of males in a male-dominated society and country, who would use it to control women instead. Indeed, one participant expressed that this statement generalised the idea of victimisation and the societal stigma of putting the blame on women. "Terri", twenty-one shared this view. "...like the kind of post just makes the idea that it is often woman's fault a lot stronger. And I think that is especially how we're in a society where we always put the blame on women a lot more." 


\section{Religious and Cultural Influences}

The majority of participants held the same beliefs that the message was one-sided and was deeply influenced by culture and religion. Indeed, participants cited that the underlying cultural upbringing of Asian women being more subservient to their male spouses encouraged them to view the issue as a female burden. They felt that this, in turn, may prevent women from acting on their own abilities and resort to relying on their husbands or male counterparts instead of tackling challenges head on as a women.

However, some participants were vocal in their distaste of the statement as it reflected conservative views of Muslim women and their religion as a whole. This small group of participants were quite aware of the taboo of commenting on religion but were still vocal about how religion played a role in supporting conservative views on gender roles and that feminism may very well be based upon the fact. Therefore, the ministry and the women of power who indeed made the statements are more likely to envision this as empowerment and not at all conservative in their point of view. "YN", twenty, states that perhaps their culture plays an important part in this. "...cultural or even their religion, because from what I know, a lot of them are Muslims. So their culture might be very different to what I myself am accustomed to".

Conversely, one participant did not show a strong reaction to this statement. Instead, she postulated that living in Malaysia meant expecting conservative points of view in topics related to feminism and gender roles. Instead, she was quite defeatist and remained staunch in her views of being apathetic as it was not out of the norm to experience waking up and seeing Malaysia on the front page of the news for conservative statements by women of authority. "Tina", thirty-two, felt that in her line of work of a mental health professional, her clients often cited that such ideologies were common and quickly accepted as the norm and were not questioned:

"It honestly didn't bring up like a strong reaction from me only because, I- I mean partly I think because of the line of work that I'm in that I hear it so often in women that that's what they are meant to be and do."

In addition, one participant felt that women from broken families were more likely to give in to the idea of conservative gender roles as a way to fit in and ensure that the same unfortunate circumstances do not occur for their own families. She held views that the demographic of women who would accept a statement such as the one made by the ministry be of a certain creed. "Ash", nineteen, expressed that women brought up by single parents or lacking in paternal parental figures may employ more conservative gender roles. "That particular part of the women who support that idea are those who were brought up by single mothers."

Malaysian tradition and culture are often cited as still being stuck in the past. Regarding the Ministry of Women, Family and Community Development's statement about Doraemon, the participants expressed how this is portrayed as backwards thinking and submission to traditional thinking. This is the image people around the world would perceive of Malaysia. Indeed, many participants were outraged by the statement and were quick to point out the macro implications that may befall the country due to the lack of progressiveness seen in other progressive countries. "Clarice", twenty-three, was very vocal on how women and men from other nations would think of Malaysia on a global scale:

"... So that already speaks about you as a nation that this is how you think about the world- women in your country... so this is how Malaysian women are treated or rather, this is how Malaysian women are expected to behave. Right?"

\section{Discussion}

This qualitative study conducted revealed that young working women in Malaysia aged between eighteen to forty years of age share mostly similar views about feminism and conservative gender roles 
in this country. Although issues on feminism and conservative gender roles were often derived by the participants as the result of culture, upbringing and religion, it was interesting to discover the underlying issues perceived by the participants on a societal level. Indeed, after in-depth analysis, feminism and conservative gender roles in Malaysia as perceived by this demographic and according to stipulated criteria are often mentioned in relation to Equality and Support of Women's Rights, Evolutionary Changes in Norms of Conservative Roles and even the Women in Positions of Power and their role in disseminating information about gender roles to the impressionable new young generation of men and women. These themes closely correlate to Liberal Feminism Theory, Poststructuralist Feminism Theory and Radical Feminism Theory respectively.

Indeed, the findings correlate with previous studies done in this field of feminism. Malaysian women are more aware of evolutionary changes in the norms of conservative gender roles as the digital age develops. This acts as a platform to educate those who would normally not be educated about the waves of feminism and the impact of gender roles that can occur. This explains the increasing number of young working women, especially in the confines of our study. Participants who criticise the statement made by the Women, Family and Community Development Ministry of Malaysia attributed this heightened awareness to the underlying implications of the statement as degrading.

Next, young working women in Malaysia are aware of the difficulties they face due to their gender in the country. Indeed, in our findings from the analyses of the participants' responses, this was often construed to the misconception of feminism being a trigger word for those who misunderstood the general direction intended by the movement especially in a Third World Country such as Malaysia. These statements are supported by previous findings in other studies. It is often stereotyped that feminist men were seen to be more feminine than non-feminist men (Gundersen, 2018) and therefore feminism remains a taboo subject in Malaysia. Some participants were visibly uncomfortable answering certain questions on their points of view on how men would perceive them if they were feminists. Moreover, it was interesting to see the progressive views some of our participants displayed over the issue of gender equality in opportunities. Indeed, besides the general consensus that the collective inequality faced in the workforce demeaned their efforts to be productive members of society and the workforce due to their gender, two participants in particular emphasised that gender as a term was outdated in today's community, which includes LGBT individuals. This issue has not been brought up in previous findings for this field of study and would be interesting research in more detail to correlate both feminism and gender roles within the LGBTQ community and their perception of the feminist movement.

The responses by Malaysian women on the issue of pay gap due to their genders were interesting. While some found that their expertise and education enabled them to get fair pay in comparison to their male counterparts, only a handful acknowledged that they had to work twice as hard to prove their position, which they did not see occur among their male counterparts. Besides, some participants cited close friendships with other female friends who complained about receiving unfair treatment and lower pay than their male counterparts. In fact, besides the three participants who cited they were paid unfairly, most, if not all, the other participants stated they were paid fairly.

Equally important were the participants' emphasis on family background and upbringing. This was mostly in the explicitness that a conservative gender role would be exhibited or at least practiced by Malaysians which may impact young working women in Malaysia and their view on gender roles as a whole. The majority of participants grew up with traditional values and conservative gender roles being the norm and only changed with time, maturing, and being exposed to new ideologies. Moreover, this relates back to previous findings in studies of the field of feminism in prevailing cultural norms. This issue is reiterated several times by many participants and therefore correlates with previous studies. Conservative ideologies of said families contributed to the sustained usage of conservative gender roles when young working women have families of their own.

On the issue of tradition, culture and religion influencing the idea of traditional roles evolving, the participants noted that the authoritative figures and bodies in Malaysia are still stuck in the past and often discuss current issues from an outdated frame of mind. The statements issued by the Women, 
Family and Community Development Ministry were considered backwards. Moreover, the findings in this study challenged the notion that the young working women in Malaysia would be submissive to traditional ideologies as many cited that if there were no barriers to overcome and without the need of financial security or more individual freedom, they would challenge the norms and inequalities head on.

This is reflected in their point of view on their agency, respect and mutual contributions for equal treatment in relationships. One participant noted the general underlying oppression Malaysian women might still be facing if this was a question that still needed to be asked.

\section{Implications}

Variation in the age group of the sample as well as having a diverse and representative sample of participants helped enhanced this study. The participants may have given overly positive views on the community's perception of gender roles and feminism in Malaysia. However, this can be interpreted as an evolving perception of the issue at hand in the country as well as having a discussion that was free and reflected the increasing awareness of this issue. It was enlightening to see the participants so readily to engage in topics that may seem taboo to other women in Malaysia such as pay gap, being subservient to husbands and even topics that are taboo in the country, such as considerations of the LGBT community. As the participants only included young working women in Malaysia, it may be hard to study the effect of spousal influences on gender roles and perception of feminism. Perhaps, having future studies include the young working males in Malaysia may benefit the research topic. Future studies could include these extra criteria for an effective gender-based analysis on feminism among young adults in Malaysia.

\section{Conclusion}

This study cast a light on the social, societal and legal implications that young working women in Malaysia may face in their day to day lives and the influences said issues may have on the implications of gender norms. This study has identified significant differences in how young working women in Malaysia perceive and are challenged by traditional gender roles. Prominent socio-cultural and structural barriers may prevent the discussion and major movement of Gender Roles and Feminism in a country where religion heavily politicises the authority of women in positions of power. Moreover, this can hinder the opportunities young working women in Malaysia may see for themselves when exiting educational settings for the workforce and may encourage the cycle of traditional gender roles that has been reinforced through tradition and upbringing. Addressing the issues of feminism and traditional and conservative gender roles in places of learning such as universities and implementing leading examples and experts in the field of Gender Studies can contribute to healthy discussions among society as a whole and help tackle the issue on a macro level.

\section{References}

Ali, Z. (2019). Feminisms in Iraq: Beyond the Religious and Secular Divide. Gender a Výzkum / Gender and Research, 20(2), 47-66. https://doi.org/10.13060/25706578.2019.20.2.483

Aston, M., Price, S., Kirk, S. F. L., \& Penney, T. (2012). More than meets the eye. Feminist poststructuralism as a lens towards understanding obesity. Journal of advanced nursing, 68(5), 1187-1194. https://doi.org/10.1111/j.1365-2648.2011.05866.x

Ariffin, R. (1999). Feminism in Malaysia. Women's Studies International Forum, 22(4), 417-423. https://doi.org/10.1016/s0277-5395(99)00039-4

Barrett, M. J. (2005). Making (some) sense of feminist poststructuralism in environmental education research and practice. Canadian Journal of Environmental Education (CJEE), 10(1), 79-93.

Beasley, C. (1999). What is feminism?: an introduction to feminist theory. SAGE. 
Beste, J. (2006). The limits of poststructuralism for feminist theology. Journal of Feminist Studies in Religion, 5-19. https://doi.org/10.2979/FSR.2006.22.1.5

Braun, V., \& Clarke, V. (2006). Using thematic analysis in psychology. Qualitative research in psychology, 3(2), 77-101. https://doi.org/10.1191/1478088706qp063oa

Brown, A. M., \& Ismail, K. J. (2019). Feminist Theorizing of Men and Masculinity: Applying Feminist Perspectives to Advance College Men and Masculinities Praxis. Online Submission, 42(1), $17-$ 35.

Elder, N. C., \& Miller, W. L. (1995). Reading and evaluating qualitative research studies. The Journal of Family Practice, 41(3), 279-285. https://doi.org/10.4135/9781483349435.n4

Feminism. (2019). In Lexico Oxford Dictionary. Retrieved from https://www.lexico.com/en/definition/feminism

Garland-Thomson, R. (2002). Integrating disability, transforming feminist theory. NWSA journal, 1-32. https://doi.org/10.1353/nwsa.2003.0005

Greaney, M. (2006). Feminism versus Post-structuralism. In Contemporary Fiction and the Uses of Theory (pp. 99-122). Palgrave Macmillan, L. https://doi.org/10.1057/9780230208070_7

Gundersen, A. B., \& Kunst, J. R. (2019). Feminist $\neq$ feminine? Feminist women are visually masculinized whereas feminist men are feminized. Sex Roles, 80(5-6), 291309.https://doi.org/10.1007/s11199-018-0931-7

Heilman, M. E. (2001). Description and prescription: How gender stereotypes prevent women's ascent up the organizational ladder. Journal of Social Issues, 57(4), 657-674. https://doi.org/ $10.1111 / 0022-4537.00234$

Izharuddin, A. (2013). The use of English in contemporary Malaysian feminist activism. Editorial Board, 37.

Jurasz, O., \& Barker, K. (2019). Online Misogyny: A Challenge for Digital Feminism?. Journal of International Affairs, In-Press.

Mann, S. A., \& Patterson, A. S. (2016). Reading feminist theory: from modernity to postmodernity. Oxford University Press.

Mann, S. A. (2013). Third wave feminism's unhappy marriage of poststructuralism and intersectionality theory. Journal of feminist scholarship, 4(4), 54-73. Retrieved from https://digitalcommons.uri.edu/jfs/vol4/iss $4 / 5$

Marsh, D., \& Stoker, G. (2002). Theories and methods in political science. Palgrave.

Mitchell, J. (1974). Psychoanalysis and feminism, Freud, Reich, Laing and women. New York.

Niranjana, T. (2010). Why culture matters: rethinking the language of feminist politics. Inter-Asia Cultural Studies, 11(2), 229-235. https://doi.org/10.1080/14649371003616326

Qiu, Q. (2019). A Comparative Study of Novel Translation under Feminist Translation Theory: A Case Study of the Two Chinese Versions of To the Lighthouse. Theory and Practice in Language Studies, 9(6), 718-722. https://doi.org/10.17507/tpls.0906.16

Oxford. (2019). In Lexico Oxford Dictionary. Retrieved from https://www.lexico.com/en/ definition/gender_role

Ramazanoglu, C. (1992). On Feminist Methodology: Male Reason Versus Female Empowerment. Sociology, 26(2), 207-212. https://doi.org/10.1177/0038038592026002003

Rickett, B. (2016). VI. Feminist psychology-poststructuralism, class and maternal subjectivities: Where are we and where should we go next?. Feminism \& Psychology, 26(3), 320326.https://doi.org/10.1177/0959353516641140

Seibold, C. (2000). Qualitative research from a feminist perspective in the postmodern era: Methodological, ethical and reflexive concerns. Nursing Inquiry, 7(3), 147-155. https:// doi.org/10.1046/j.1440-1800.2000.00063.x

St. Pierre, E. A. (2000). Poststructural feminism in education: An overview. International journal of qualitative studies in education, 13(5), 477-515. https://doi.org/10.1080/09518390050156422

Yick, A. G. (2001). Feminist theory and status inconsistency theory: Application to domestic violence in chinese immigrant families. Violence Against Women, 7(5), 545-562. https://doi.org/10.1177/10778010122182596

Zucker, A. N., \& Bay-Cheng, L. Y. (2010). Minding the gap between feminist identity and attitudes: The behavioral and ideological divide between feminists and non-labelers. Journal of personality, 78(6), 1895-1924. https://doi.org/10.1111/j.14676494.2010.00673 


\section{Appendix A}

\section{Sample of Interview Questions}

1. How would you describe feminism?

2. What do you think influenced your idea of what feminism is?

3. Do you consider yourself a feminist? If yes, why? If no, why not?

4. Has your idea of feminism changed over time? If yes/no, what made it change?

5. Would you consider that you are paid fairly in comparison to your male colleagues?

6. What do you think of women who make more for a living than men?

7. If you were to earn more than your husband, do you think that would be accepted in your household?

8. How would you describe gender roles?

9. What do you think influenced your idea of what gender roles are?

10. What gender roles come to mind when females are concerned?

11. Has your idea of gender roles changed over time? If yes/no, what contributed to that change?

12. The Women, Family and Community Development Ministry of Malaysia mentioned that females, especially wives, should "act like Doraemon" and submit to their husbands by making them happy, cooking for them and putting on makeup on as well as dressing up at home for him. How does this make you feel? What are your thoughts on this advice? 


\section{Appendix B}

\section{Sample of Interview Transcript}

(Introduction)

I: We'll start it off straight away with a very simple question, how would you describe feminism?

P: $\quad$ Okay, how would I describe femi-feminism? Um, generally I think it's... a social movement, whereby people feel like, um, you know, there has to be equality for...uh both genders la or basically like, you know, any any person, regardless of gender I guess depending on what they choose to identify themselves and um...yeah, it's basically involves like um, I guess, the political side, the social side and also maybe the economical side la so but I think a lot of times- Hold on, let me get my (laughs)

I: It's alright take your time

P: Yeah, basically it's a movement of people who feel that, you know, they believe that, you know, all genders should have the same treatment la whether or not either nice, political, economical and socially. Yeah. 


\section{Appendix C}

\section{Sample Consent Form}

\begin{tabular}{|c|c|c|}
\hline $\begin{array}{l}\text { TAYLOR'S } \\
\underline{\text { UNIVERSITY }} \\
\text { wisdom - integrity - tecellence }\end{array}$ & MODEL CONSENT FORM & $\begin{array}{ll}\text { Doc. Ref. :TU-ACA-FORM-HE-App3 } \\
\text { Effective Date } & : 24 \text { April } 2014 \\
\text { Revision } & : 1.0 \\
\text { Page } & : 1 \text { of } 1 \\
\text { Approved By } & : \text { Council } \\
\text { Approval Date } & : 9 \text { January } 2014\end{array}$ \\
\hline
\end{tabular}

School of Liberal Arts and Sciences

Goh lan Shen

No. 1, Jalan Taylor's, 47500 Subang Jaya, Selangor Darul Ehsan, Malaysia.

20 April 2020

\section{CONSENT FORM}

Feminism and View of Young Working Women in Malaysia of Conservational Gender Roles

I have read, understood the description and purpose of the above-named project (as in the Patient Information Sheet).

I have been told about the nature of the research in terms of methodology, possible adverse effects and complications (as in the Patient Information Sheet). After knowing and understanding all the possible advantages and disadvantages of this clinical research, I voluntarily consent of my own free will to participate in the clinical research specified above.

I understand that I can withdraw from this clinical research at any time without assigning any reason whatsoever and in such a situation shall not be denied the benefits of usual treatment by the attending doctors.

I note that the project has been reviewed and approved by the Taylor's University Human Ethics Committee.

$\begin{array}{ll}\text { NAME } & : \\ \text { Signature } & : \\ \text { Date } & :\end{array}$




\section{Appendix D}

\section{Sample Information Sheet}

\begin{tabular}{|c|c|c|}
\hline $\begin{array}{l}\text { TAYLOR'S } \\
\frac{\text { UNIVERSITY }}{\text { wiston - integnity - Exellence }}\end{array}$ & $\begin{array}{c}\text { MODEL PATIENT } \\
\text { INFORMATION SHEET }\end{array}$ & $\begin{array}{l}\text { Doc. Ref. :TU-ACA-FORM-HE-App2 } \\
\text { Effective Date : } \\
\text { Revision } \quad: \\
\text { Page } \quad: 1 \text { of } 1 \\
\text { Approved By }: \text { Council } \\
\text { Approval Date : }\end{array}$ \\
\hline
\end{tabular}

Taylor's University Letterhead

School of Liberal Arts and Sciences

You are invited to participate as a subject in the research project "Feminism and View of Young Working Women in Malaysia of Conservational Gender Roles" The aim of this project is to investigate views of young working women ages 18-40 years of age, on conservational gender roles. We wish to determine the general view point of feminism in this said age category.

Your involvement in this project will be to partake in an interview which would take around 45 mins to an hour depending on how you answer, and the right to withdraw from the project at any time, including withdrawal of any information provided.

In the performance of the tasks and application of the procedures there are possible risks of psychological discomfort or inconvenience, where if needed psychological services can be offered.

The results of the project may be published, but you may be assured of the complete confidentiality of data gathered in this investigation: the identity of participants will not be made public without their consent.

To ensure anonymity and confidentiality, your information will only be accessible to the researchers involved in this project and the information recorded will be deleted after we have used the data for the research purposes.

The project is being carried out as a requirement for our Bachelor of Psychology Degree by Goh lan Shen under the supervision of Ms. Pang Chia Yee, who can be contacted at $+60122398510 /+60123727236$ respectively. They will be pleased to discuss any concerns you may have about participation in the project.

The project has been reviewed and approved by the Taylor's University Human Ethics Committee. 


\section{Appendix E}

\section{Sample Recruitment Script}

\section{Recruitment Script}

I am writing to invite you to participate in an online interview on Feminism and View of Young Working Women in Malaysia of Conservational Gender Roles. The online interview is part of my class project that I am involved in. My task is to recruit young working women aged 18-40 years old to participate in an online interview on said topic for course credit. The online interview will take about 45 minutes to 60 minutes to complete. The online interview will not exceed the allotted time. Your responses will be kept confidential, and only the data and findings will be presented in the report. The interview will be conducted online or through a calling application. All applications are free and fall to the choice of the participant. The applications include Skype, Zoom, or WhatsApp messenger. Participation in this study is voluntary and you may withdraw from participation at any time. Data will only be used for this course project, will be managed by the lecturer acting as supervisor, and will be destroyed within the 4 months it will take for this study to be conducted. If you have any questions about your rights as a research participant you may contact the lecturer supervising this class project, Pang Chia Yee, School of Liberal Arts and Sciences, Taylor's University, (012-3727236). Thank you in advance for your consideration in completing this important course project! 


\section{Appendix F}

\section{Sample Debriefing Script}

\section{Debriefing Script}

Thank you for participating in this research. The next step will be transcribing the interview into text for analysis. I shall transcribe this interview into text, and erase the recording of our interview once an electronic copy and paper copy have been made. The text will not contain any identifying information. I shall analyse the text of the interviews for themes and taken-for-granted ideas about the world that describes the range of responses to my questions. Based on this analysis, I shall write a report of the project for course credit. The copy of the Participant Consent Form that your return to me will be securely given to Pang Chia Yee, lecturer and overseer of this assignment. The forms will be destroyed and any recordings erased after they have been used for analysis for the report, therefore, within the four months of this project which will run from April 2020 to July 2020. If you would like to be informed of the results of the research, please contact Pang Chia Yee, the supervisor of the research (e-mail: ChiaYee.Pang@taylors.edu.my), ph. (012-3727236). I can also provide you with a copy of my research report should you wish to read it. 


\section{Appendix G}

\section{Sample of Service Sheet}

\section{Service Sheet}

In the course of this study, although unintended or unknowingly so, information about feminism and gender roles may stir up intense personal significance for some participants.

Therefore, if you find that you are troubled by any o the information collected in the course of this study, and need support of counselling, please be sure to pursue external support by looking for a counsellor and/or a social service and/or helpline.

A sample of counselling and social services resources that are available in Malaysia are as follows:

Disclaimer: We do not assume any responsibility for the quality of the services offered by the following organizations.

\section{These services provided FREE}

Lifeline Association of Malaysia

Hotline: (063) $92850039 /(063) 92850279 /(063) 92850049$

71-2nd Floor, Jin Jejaka 255100

TMN MALURI

Hotline: (063) 92850039

Hotline: (063) 92850279

Hotline: (063) 92850049

The Befrienders Kuala Lumpur

Hotline: (03) 79568144 / (03) 79568145

95 Jalan Templer

Petaling Jaya

46000

SELANGOR DARUL EHSAN

WOMEN'S AID ORGANIZATION (WAO) 
Malaysian Journal of Social Sciences and Humanities (MJSSH), Volume 6, Issue 8, (page 463 - 485), 2021

DOI: https://doi.org/10.47405/mjssh.v6i8.931

Contact Number:

WAO Hotline: +603 79563488

WAO SMS/WhatsApp line, TINA : +6018 9888058

General Enquiries: 0379575636 / 0636

ALL WOMEN'S ACTION SOCIETY (AWAM)

Telephone helpline:

03-78770224

E-Mail: awam@awam.org.my

Website: https://www.facebook.com/AWAMMalaysia/ 


\section{Appendix $\mathrm{H}$}

\section{Sample of Approval from Research Ethics Committee}

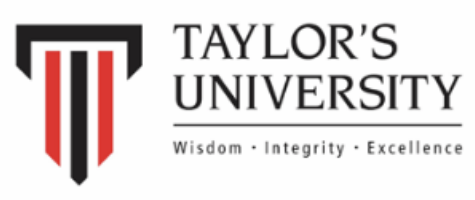

Reference No. : HEC 2020/045

Date $\quad: 26^{\text {th }}$ June 2020

Dear Ms Pang Chia Yee \& Goh Lan Shen,

Human Ethics Application: Feminism and View of Young Working Women in Malaysia of Conservational Gender Roles

With reference to your application received on June 2020, I wish to inform you that the Scientific Committee deliberated your application and has concluded that your study poses no ethical issues of concern. This approval is valid until the project end date of July 2020 .

Please adhere to the stated methodology as written and should a change be required, kindly write in to the TUEC to detail the changes sought for approval prior to implementation.

We wish you all the best in your project.

Sincerely,

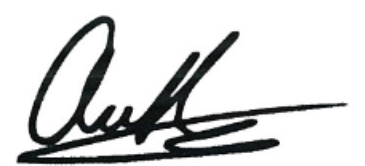

Anthony Ho, PhD

Chair, Human Ethics Committee, Taylor's University 


\section{Appendix I}

Table 1

Thematic Table

\begin{tabular}{|c|c|c|}
\hline Themes & Sub-themes & Sub-themes examples \\
\hline \multirow[t]{2}{*}{$\begin{array}{l}\text { Equality and Support of } \\
\text { Women's Rights }\end{array}$} & $\begin{array}{l}\text { Gender Equality and Advocacy of } \\
\text { Women Rights }\end{array}$ & $\begin{array}{l}\text { "...this becomes a problem } \\
\text { because there are so } \\
\text { many people } \\
\text { nowadays that are } \\
\text { gender neutral, what } \\
\text { about the queer and } \\
\text { the LGBT. You } \\
\text { know, there are } \\
\text { people that do not } \\
\text { want to conform to a } \\
\text { gender because they } \\
\text { are gender fluid." } \\
\text { (Clarice, age 23) }\end{array}$ \\
\hline & $\begin{array}{l}\text { Family Background and } \\
\text { Upbringing }\end{array}$ & $\begin{array}{l}\text { “... she helped me and my } \\
\text { brother see that, hey, } \\
\text { you know what, no } \\
\text { matter whether you're } \\
\text { a male or female, you } \\
\text { are equally important, } \\
\text { and you can do } \\
\text { whatever you want to } \\
\text { do." (Jo, age 27) }\end{array}$ \\
\hline
\end{tabular}

Evolutionary Changes in Norms of Conservational Roles
Respect for equal treatment in relationships.

Fairness of salary based on education and expertise.
“...I think this is more of an Asian uhh you know mindset, where you know, women have to earn much lesser and men have to earn more, and things like that. If suddenly they see the woman is earning more than they tend to compare, they tend to talk back you know" (Kamal, age 33)

“...I feel like a women, you need to do a lot more to prove what you're worth, and um, it's really a horrible feeling... They (men) don't need to prove themselves, so what they need to do is the bare minimum." (Sha, age 27) 
Women in Positions of Power Disseminate Obsolete

Information on Gender Roles
Inappropriate Statements and Outdated Mentality
Underlying Implications of Patriarchal System

Religious and Cultural Influences

“... I see where the Ministry of Women was coming from, in a sense that they wanted to- they wanted women to lay low and to not cause any fights by doing this, but it shouldn't just be the woman's responsibility!" (Deidra, age 32)

“...empowering men like those who actually already have a very traditional thinking that oh, we must, should do this and do that. So those men who read that will stand even more strongly on their own point of view, and then they would use that to oppress their own partners." (Ash, age 19)

"...cultural or even their religion, because from what I know, a lot of them are Muslims. So their culture might be very different to what I myself am accustomed to". (YN, age 20) 